Smart Innovation, Systems and Technologies 265

\title{
A. N. R. Reddy
}

- Deepak Mara

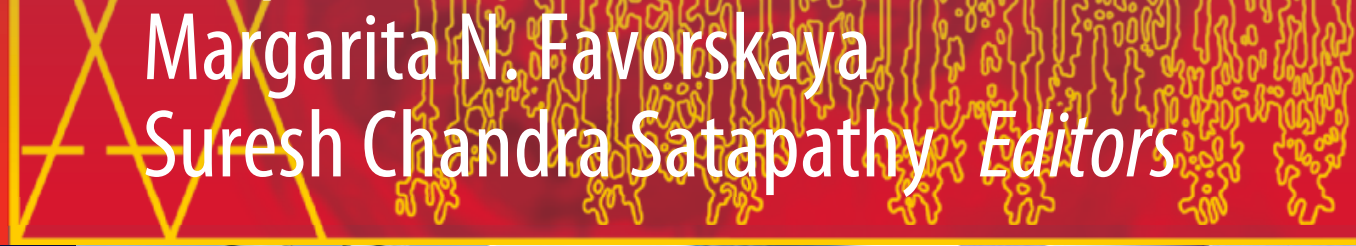

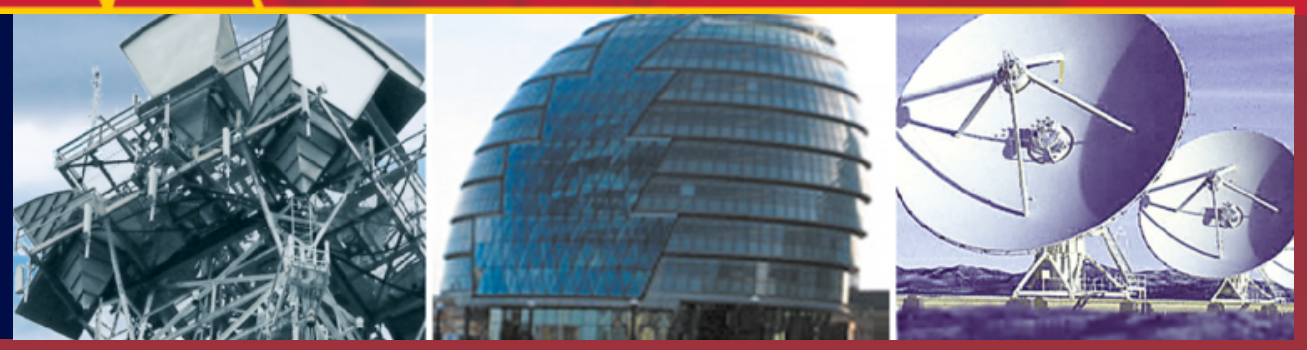

Intelligent

Manufacturing

and Energy

Sustainability

Proceedings of ICIMES 2021

Springer 


\section{Editors}

\author{
A. N. R. Reddy \\ Department of Mechanical Engineering \\ Malla Reddy College of Engineering \\ and Technology \\ Hyderabad, India
}

\author{
Margarita N. Favorskaya \\ Reshetnev Siberian State University \\ of Science and Technology \\ Krasnoyarsk, Russia
}

\author{
Deepak Marla \\ Department of Mechanical Engineering \\ Indian Institute of Technology Bombay \\ Mumbai, India
}

\author{
Suresh Chandra Satapathy \\ Kalinga Institute of Industrial Technology \\ Bhubaneswar, India
}

ISSN 2190-3018

ISSN 2190-3026 (electronic)

Smart Innovation, Systems and Technologies

ISBN 978-981-16-6481-6 ISBN 978-981-16-6482-3 (eBook)

https://doi.org/10.1007/978-981-16-6482-3

(C) The Editor(s) (if applicable) and The Author(s), under exclusive license to Springer Nature

Singapore Pte Ltd. 2022

This work is subject to copyright. All rights are solely and exclusively licensed by the Publisher, whether the whole or part of the material is concerned, specifically the rights of translation, reprinting, reuse of illustrations, recitation, broadcasting, reproduction on microfilms or in any other physical way, and transmission or information storage and retrieval, electronic adaptation, computer software, or by similar or dissimilar methodology now known or hereafter developed.

The use of general descriptive names, registered names, trademarks, service marks, etc. in this publication does not imply, even in the absence of a specific statement, that such names are exempt from the relevant protective laws and regulations and therefore free for general use.

The publisher, the authors and the editors are safe to assume that the advice and information in this book are believed to be true and accurate at the date of publication. Neither the publisher nor the authors or the editors give a warranty, expressed or implied, with respect to the material contained herein or for any errors or omissions that may have been made. The publisher remains neutral with regard to jurisdictional claims in published maps and institutional affiliations.

This Springer imprint is published by the registered company Springer Nature Singapore Pte Ltd. The registered company address is: 152 Beach Road, \#21-01/04 Gateway East, Singapore 189721, Singapore 


\section{Contents}

1 An Experimental Investigation into the Performance Characteristics of $\mathrm{TiO}_{2}$ /Ethylene Glycol Nanofluid Flowing in a Horizontal Counterflow Heat Exchanger . . . . . . . . . . . . 1 Thembelani Sithebe and Veeredhi Vasudeva Rao

2 Calibration of Industrial Fanuc 430iF Series Robot Arm

Mazleenda Mazni, Muhammad Azmi Ayub, and Norhafiza Muhammad

3 Development of Batch Type Convection Dryer for Fish

Cracker Manufacturing

Muhammad Naim Leman, Shahrol Mohamaddan,

Ana Sakura Zainal Abidin,

Mohamad Syazwan Zafwan Mohamad Suffian, Khairul Fikri Tamrin,

Rubiyah Baini, and Akihiko Hanafusa

4 An Experimental Investigation on Mechanical and Tribological

Behaviour of (AZ91D Mg Alloy + Graphene) Metal Matrix

Composite

N. Satish Kumar, G. G. Sozhamannan, and V. S. K. Venkatachalapathy

5 Investigation of Wear and Mechanical Properties of Aluminium Hybrid Composites: Effect of Addition of $\mathrm{SiC} / \mathrm{B}_{\mathbf{4}} \mathrm{C}$ Through

Casting Process .

S. Sunil Kumar Reddy, C. Sreedhar, and S. Suresh

6 Effect of Stress on Ferroelectric, Energy Storage and Harvesting Properties of 0.4BZT-0.6BCT Ceramics

Nishchay Saurabh and Satyanarayan Patel

7 Survey of Nanosensors and Nano-heterostructures Priya Chaudhary, Sonam Gour, and Amit Rathi 
8 Recognition of Facial Expressions Based on Detection of Facial Components and HOG Characteristics

K. A. Anu and N. Ali Akbar

9 Optimization of Pneumatic Extrusion Machining Method Process Parameters on Polycaprolactone (PCL) Material . . . . . . . . . . . 85

O. Y. Venkata Subba Reddy, A. N. R. Reddy, and V. Venkatesh

10 A Comparison of Mixing and Displacement Ventilation System in an Office Environment Using Computational Fluid Dynamics . . .

Mohammed Abdul Hameed Khan, Chanfiou Ahmed Mboreha, and Hazem Abdelrahman

11 Performance Study and Analysis of an UAV Airfoil at Low

Reynolds Number

Ramanan Gopalakrishnan, Neela Rajan Rajadurai Ramakrishnan,

Bino Prince Raja Dennis, and Anton Savio Lewise Kuzhanthai

12 Life Cycle Assessment Based Environmental Footprint

of a Battery Recycling Process . . . . . . . . . . . . . . . . . . . . 115

Arvind Kumar, Abhishek Gupta, Shalini Verma,

Akshoy Ranjan Paul, Anuj Jain, and Nawshad Haque

13 Review on the Structural Components of Floating Photovoltaic

Covering Systems

Nagananthini Ravichandran, Nagavinothini Ravichandran, and Balamurugan Panneerselvam

14 Performance and Emission Test of C.I. Engine Using Biodiesel . . .

P. V. Chandra Sekhara Rao, B. Renuka Swathi, and Aluri Manoj

15 Evaluation on the Diseased Damage Grading Model of the Fresh

Destemmed Chilli Fruits . . . . . . . . . . . . . . . . . . . . . . 147

Quoc-Khanh Huynh, Chi-Ngon Nguyen, Jeng-Rong Ho,

Hong-Phuc Vo-Nguyen, and Van-Cuong Nguyen

16 On the Study and Analyses of "Vertical Farming-The Future

of Agriculture" via Various Hydroponic Systems

Tanishi Mathur and Senthil Arumugam Muthukumaraswamy

17 Design and Analysis of Progressive Tool for Glass Brackets . . . . . 167 Nagaveni Thallapalli, K. Laxman Kumar, and S.

B. Manikanta Katepalli

18 Analysis of Strain Hardening Behavior of ARMCO Iron After

Severe Plastic Deformation Using K-M Plots

Vindala Poojitha, T. Raghu, and V. Pandurangadu 
19 Optimization of Process Parameters for Friction Stir Spot Welding Using Dissimilar Metals

Pitala Adithya, B. D. Y. Sunil, and C. Labesh Kumar

20 Development of a Preliminary Approach for Automatic

Generation of the CAD Model of the Spur Gear

Shubham Agarwal, Gurunandan Jamalpur, Nikhil Tuljapurkar, and Jayakiran Reddy Esanakula

21 Design of a Robot for the Welfare of the Poultry

Rushikesh Hanuman Yede and Skylab Paulas Bhore

22 A Despeckling Filter for Ultrasound Images Based on Cellular Automata Approach

Ankur Bhardwaj, Sanmukh Kaur, Manoj Shukla, and Anand Prakash Shukla

23 Development of a Preliminary Approach for Automatic CAD

Model Generation of the IC Engine Piston

Nikhil Tuljapurkar, Gurunandan Jamalpur, Shubham Agarwal, and Jayakiran Reddy Esanakula

24 Temperature Control Methodology for Catalytic Convertor to Reduce Emissions and Catalyst Aging

S. Mithun Vaisnav and Sivanesan Murugesan

25 Solar Powered Autonomous Robotic Car Using for Surveillance

V. Premchandran, M. Karthikkumar, V. Thamizharasan, and E. Sathish

26 Design and Simulation of Hybrid Microsystem and Its Effect on the Environment Using Homer Software

Alok Kumar and Shelly Vadhera

27 Battery Charging Using Solar Photovoltaic System

with Maximum Power Point Tracking

Siddharth Samaddar, Ujjwal Rastogi, Soham Tyagi, and Saurabh Mishra

28 Design and Analysis of Hydraulic Machining Fixture for a Drifter

Bit of a Top Hammer .

Nagaveni Thallapalli, G. Sudheer Kumar Reddy, J. Jaswanth Raju,

S. B. Manikanta Katepalli, and Vineela Chippe

29 Inverse Kinematic Analysis of PUMA 560 for Vision Systems . . . 285 Navya Mohan, Athul Thomas, P. P. Prasanth, M. S. Midhun, and James Kurian 
30 Experimental Investigation on Portable Refrigerating Bottle . . . . 295 Shiva Kumar Reddy Devasani, Sudeshna Vodnala, and K. Krishnamurthy

31 Challenges of Introducing Lean Six Sigma, IoT in Industry 4.0, and Supply Chain Management: A Review . . . . . . . . . . . . 303 Vedant Kale, Chetan Katke, Shailendra Dayane, and Prashant Thakar

32 Development of Novel Concrete for Recharging the Ground Water Levels in the Rocklands of Urban Areas

Venu Malagavelli, A. Jagadish Babu, S. Siva Rama Krishna, and V. Suryaprakash Reddy

33 Vision-Based Real-Time Hand Wash Accuracy Prediction

C. Kavinkumar, S. Tony Geefus, and Prashant R. Nair

34 Development and Analysis of Efficient Dispatching Rules for Minimizing Flow Time and Tardiness-Based Performance Measures in a Job Shop Scheduling

S. Ashwin, V. Shankaranarayanan, Damien lamy,

S. P. Anbuudayasankar, and M. Thenarasu

35 Vibration Measurement Using a Low-Cost MEMS Accelerometer Kit for the Education . . . . . . . . . . . . . . . . . . . . . . . . . . . 347

Syed Faizan Shah and Skylab Paulas Bhore

36 Disease Prediction by Stacking Algorithms Over Big Data from Healthcare Communities .

M. Hema Latha, A. Ramakrishna, B. Sudarsha Chakravarthi Reddy, Ch. Venkateswarlu, and S. Yamini Saraswathi

37 Experimental Investigation on Performance and Emission Characteristics of Mixture of Sunflower and Soybean Biodiesels . . . . . . . . . . . . . . . . . . . . . . . 365 Shiva Kumar Reddy Devasani and K. Krishna Murthy

38 Experimental Study of Nano Additive-Added Biodiesel Blend to Improve the Engine Performance Characteristics 381

B. Jayakrishnan and D. Senthilkumar

39 Detection of Fake and Clone Accounts in Twitter Using Classification and Distance Measure Algorithms.

S. Siva Rama Krishna, K. Umakanth Reddy, T. Anji Reddy, A. Saiteja, and R. Sumanjali

40 Review of Recent Developments in Sustainable Traffic Management System . 401

Bhawini Sharma and Jai Kumar Maherchandani 
41 Automatic Machine for Round Welding Using Programmable Logic Controller (PLC)

Gautam Gupta, Rajanpreet Singh, and Anant Kumar Singh

42 Road Surface Quality Monitoring Using Machine

Learning Algorithm

Prabhat Singh, Abhay Bansal, Ahmad E. Kamal, and Sunil Kumar

43 Optimization of Electric Vehicle Ladder Frame Chassis Based on Material and Thickness Parameter Variation Using FEA

Yash Keskar, Sourabh Damkale, and Pankaj Dhatrak

44 Smart Personal Task Scheduler

N. Sai Swaroop Krishna, A. Krishna Tej, and M. Suchithra

45 Employee Attrition Prediction Using Machine Learning

Comparative Study

Shobhit Aggarwal, Manik Singh, Shivam Chauhan, Mugdha Sharma, and Deepti Jain

46 Optimising Effect of Resonance by Harmonic Analysis

of Ethylene Propylene Diene Monomer (EPDM) Engine Mount . . 467 Tripti Khulbe and Vikas Rastogi

47 Design and Analysis of Multi-Tool Light Agricultural Vehicle . . . .

K. Vijay Kumar, Ismail Kakaravada, and Y. Dilip Kumar

48 Identification of Alzheimer's Disease Using Various Deep

Learning Techniques-A Review

Ragavamsi Davuluri and Ragupathy Rengaswamy

49 UPQC with AI Techniques for Power Quality Improvement

M. Sharanya, Basavaraja Banakara, and M. Sasikala

50 Field Investigation of Fundamental Frequency of Structures

Using Frequency Domain Vibration Analysis

Saugato Dey, Saikat Kr Shome, and Kalyan Kr Mistry

51 On the Study and Analysis of Automated Aquaponics System

Using AVR Microcontroller

Alka Sathyan, Senthil Arumugam Muthukumaraswamy, and Habibur Rahman

52 Stack-based Outbound Operation Method for Steel Plate Yard in Shipbuilding .

Lebao $\mathrm{Wu}$ and Zuhua Jiang

53 Investigations on Microstructures by Using Friction

Stir Processing

Bazani Shaik, G. Harinath Gowd, B. Durga Prasad, and P. Siddik Ali 
54 Comparative Study of Plain and Twisted Ducts in Heat Transfer

M. Udaya Kumar and Gadi Karthik

55 Performance Evaluation of a Predictive and PID Control Applied to a Didactic Flow Regulation Process

Wilson Guambo, Byron P. Corrales, Luigi O. Freire, and Mauro D. Albarracin

56 Analysis Factors in the Adoption of Digital Manufacturing Technologies in SMEs

Luisa Maria Tumbajoy and Mariela Muñoz-Añasco

57 Analysis of Microstructural Features and Corrosion Resistance of Cryogenic Burnished and Hydroxyapatite Powder Burnished Titanium Alloy

Samatham Madhukar, Gyara Ajay Kumar, Dharamkar Sai Suman, Syed Azam Pasha Quadri, and U. Ashok Kumar

58 Detection of Micro-defects on Metal Screw Surfaces Based on Faster Region-Based Convolutional Neural Network .

Mohd Nor Azmi Ab Patar, Muhammad Azmi Ayub,

Nur Aainaa Zainal, Muhammad Aliff Rosly, Hokyoo Lee, and Akihiko Hanafusa

59 Effects of Rotation Speeds on Electrical Submersible Pump Performance Under Two-Phase Flow

Abdulqader Hasan, Salman Shahid, Sharul Sham Dol,

Mohamed S. Gadala, Mohd Shiraz Aris, and Mohammed Alavi

60 Design of Electrical Screwdriver Using Arduino and Planetary

Gear System .

Rajanpreet Singh, Gautam Gupta, and Gaganpreet Kaur

Author Index 


\title{
Chapter 3 \\ Development of Batch Type Convection Dryer for Fish Cracker Manufacturing
}

\author{
Muhammad Naim Leman, Shahrol Mohamaddan, \\ Ana Sakura Zainal Abidin, \\ Mohamad Syazwan Zafwan Mohamad Suffian, Khairul Fikri Tamrin, \\ Rubiyah Baini, and Akihiko Hanafusa
}

\begin{abstract}
Manual production of fish cracker is inherenly inefficient with low productivity. Mechanisation and automation of the drying process which constitutes a major process would contribute to increase production. In this study, a batch type convection dryer for fish cracker with a capacity of $2 \mathrm{~kg}$ was developed. The prototype with a dimension of $89-\mathrm{cm}$ length, $72-\mathrm{cm}$ width and $60-\mathrm{cm}$ height consists of a drying chamber, moving tray, transmission system, heating element and control system. A moving tray concept was applied for the machine design. The maximum temperature that can be reached in the chamber without load is $40.0^{\circ} \mathrm{C}$. Two different air velocities of $1.5 \mathrm{~m} / \mathrm{s}$ and $2.0 \mathrm{~m} / \mathrm{s}$ were applied in both simulation and experimental study. The higher air velocity was observed to shorten the time
\end{abstract}

\footnotetext{
M. N. Leman

Department of Mechatronics Technology, Industrial Training Institute, 94300 Kota Samarahan, Sarawak, Malaysia

M. N. Leman · S. Mohamaddan $(\varangle) \cdot$ A. Hanafusa

Department of Bioscience and Engineering, College of Systems Engineering and Science, Shibaura Institute of Technology, Fukasaku 307, Saitama 337-8570, Japan e-mail:mshahrol@ shibaura-it.ac.jp
}
A. Hanafusa
e-mail: hanafusa@shibaura-it.ac.jp

S. Mohamaddan · A. S. Z. Abidin · M. S. Z. M. Suffian · K. F. Tamrin Department of Mechanical and Manufacturing, Faculty of Engineering, Universiti Malaysia Sarawak, 94300 Kota Samarahan, Sarawak, Malaysia e-mail: zaasakura@unimas.my

M. S. Z. M. Suffian

e-mail: msmsyazwan@unimas.my

K. F. Tamrin

e-mail: tkfikri@unimas.my

R. Baini

Department of Chemical and Energy Sustainability, Faculty of Engineering, Universiti Malaysia Sarawak, 94300 Kota Samarahan, Sarawak, Malaysia

e-mail: ruby@unimas.my

(C) The Author(s), under exclusive license to Springer Nature Singapore Pte Ltd. 2022

A. N. R. Reddy et al. (eds.), Intelligent Manufacturing and Energy Sustainability,

Smart Innovation, Systems and Technologies 265,

https://doi.org/10.1007/978-981-16-6482-3_3 